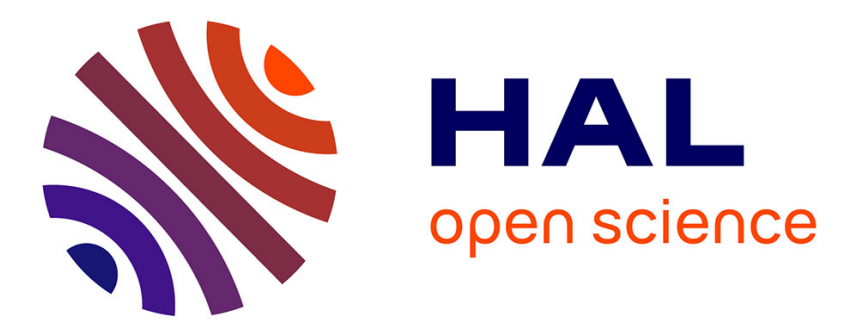

\title{
Optimizing fuel consumption and pollutant emissions of gasoline-HEV with catalytic converter
}

Pierre Michel, Alain Charlet, Guillaume Colin, Yann Chamaillard, Gérard Bloch, Cédric Nouillant

\section{- To cite this version:}

Pierre Michel, Alain Charlet, Guillaume Colin, Yann Chamaillard, Gérard Bloch, et al.. Optimizing fuel consumption and pollutant emissions of gasoline-HEV with catalytic converter. Control Engineering Practice, 2017, 61, pp.198-205. 10.1016/j.conengprac.2015.12.010 . hal-01250452

\section{HAL Id: hal-01250452 \\ https://hal.science/hal-01250452}

Submitted on 4 Jan 2016

HAL is a multi-disciplinary open access archive for the deposit and dissemination of scientific research documents, whether they are published or not. The documents may come from teaching and research institutions in France or abroad, or from public or private research centers.
L'archive ouverte pluridisciplinaire HAL, est destinée au dépôt et à la diffusion de documents scientifiques de niveau recherche, publiés ou non, émanant des établissements d'enseignement et de recherche français ou étrangers, des laboratoires publics ou privés. 


\title{
Optimizing fuel consumption and pollutant emissions of gasoline-HEV with catalytic converter
}

\author{
Pierre Michel $^{\mathrm{a}, \mathrm{b}, *}$, Alain Charlet ${ }^{\mathrm{a}}$, Guillaume Colin ${ }^{\mathrm{a}}$, Yann Chamaillard ${ }^{\mathrm{a}}$, \\ Gérard Bloch ${ }^{\mathrm{c}}$, Cédric Nouillant ${ }^{\mathrm{b}}$ \\ ${ }^{a}$ Laboratoire PRISME, Université d'Orléans \\ ${ }^{b}$ PSA Peugeot Citroën, Direction Recherche Innovation 83 Technologies Avancées (DRIA) \\ ${ }^{c}$ Centre de Recherche en Automatique de Nancy (CRAN), Université de Lorraine, CNRS
}

\begin{abstract}
Because of more and more stringent vehicle emission standards, Hybrid Electric Vehicles (HEV) are developed. Gasoline-HEV are equipped with 3-Way Catalytic Converter (3WCC). So the energy management systems of such vehicles, which must reduce not only fuel consumption, but also vehicle pollutant emissions, have to consider the 3WCC heating. A pollutant constrained energy management strategy is presented. A 3WCC multi-0D model is built from physical equations, with a good complexity-performances compromise. An off-line optimal strategy allows the joint minimization of pollution and fuel consumption with only one parameter to tune, while considering all the standardized pollutant emissions. This strategy reduces significantly the vehicle emissions for a minor fuel consumption increase and leads to define 3WCC smart heating. Thus an on-line smart heating strategy is implemented in a HyHIL (Hybrid Hardware In the Loop) test bench, reducing the pollutant emissions of the classical charge sustaining strategy by $30 \%$ for $C O$ and $10 \%$ for $N O_{X}$.
\end{abstract}

Keywords: Hybrid vehicle, pollutant emission, catalytic converter (3WCC) modeling, energy management, optimal control

\footnotetext{
This article is an extended version of Catalytic converter modeling for optimal gasolineHEV energy management presented at the 19th IFAC World Congress [1]

* Corresponding author

Email address: pierre.michel.esstin@gmail.com (Pierre Michel)
} 


\section{Introduction}

The electrical hybridization of a conventional car powertrain can decrease the fuel consumption by various means, namely recuperative braking, Stop \& Start or energy management. However, the energy management strategy

5 impacts the Hybrid Electric Vehicle (HEV) operation particularly in terms of pollutant emissions. Thus, a strategy aiming at reducing fuel consumption while respecting pollutant emissions standards has to consider the 3-Way Catalytic Converter (3WCC). For a gasoline engine, the 3WCC temperature dynamics plays a key role in pollutant emission.

10 Historically, the optimal energy management strategies were built to ensure a minimal fuel consumption, for a trip known a priori, most often a driving cycle. Usually this is done by using either Dynamic Programming (DP), derived from Bellman's principle, 2], or the Pontryagin Minimum Principle (PMP), [3], from quasistatic HEV models. The only dynamics considered in these off-line strategies concerns the battery State Of Charge (SOC).

More recent off-line strategies take into account additional considerations, such as pollutant emissions. Optimal strategies are developed with the PMP to minimize a tradeoff between engine pollutant emission and fuel consumption flow rates with the PMP method, see [4] and [5] for diesel-HEV. PMP and DP approaches were compared in [6] to solve the minimization problem for gasoline-HEV, with similar results. Due to the crucial influence of the 3WCC temperature on the conversion, strategies consider the 3WCC temperature as a second state and minimize trade-offs between fuel consumption and vehicle pollutant emissions. Such strategies are obtained with the PMP [7, 8, 6, 9, 10, 11], the deterministic DP [12, 13] or stochastic DP [14]. Using the PMP, previous works [6, 9, 11] show better results by minimizing vehicle pollutant emissions instead of engine pollutant emissions.

The present work proposes an energy management strategy optimizing both fuel consumption and vehicle pollutant emissions. The strategy is tuned with a high-fidelity model, used by PSA Peugeot Citroën to evaluate HEV fuel consumption. As the pollutant constraint has only recently been considered in energy management, this model does not include the 3WCC. Thus, this latter has been considered through a control-oriented model, simultaneously accurate and computationally inexpensive. Simulations results identify an attractive compromise between fuel consumption and pollutant emissions. Then, a heuristic strategy is deduced from the results and experimentally validated with a HyHIL (Hybrid Hardware In the Loop) test bench. 
The main contributions of the present work are the use of a multi-0D 3 WCC model with conversion maps instead of a 0D model with conversion functions as in [7, 8, 12], the introduction of a one-parameter performance index in the optimization making it possible a simple minimization of all the pollutant species defined in the standards [1, the proposition of a $3 \mathrm{WCC}$ heating strategy reducing pollutant emissions for a gasoline-HEV, which can be on-line implemented.

45 The rest of the paper is organized as follows. Sect. 1 proposes a multi-0D 3 WCC model, which is accurate but sufficiently simple to be included in the HEV model. In Sect. 2, the 3WCC model is parametrized and validated from test bench experiments. Next, Sect. 3 describes the energy management strategy optimizing both the fuel consumption and vehicle pollutant so emissions. This optimal strategy considers the 3WCC temperature dynamics and minimizes a one-parameter performance index. Then, Sect. 4 describes the HyHIL test bench and two heuristic strategies deduced from the off-line optimal strategies results. The heuristic strategies are on-line implemented and results are presented before giving some conclusions.

\section{3WCC model}

The 3WCC model is a multi-0D model based on the physical equations. This modeling choice ensures a good simplicity/accuracy compromise to be implemented in a high-fidelity HEV model with the number of zones to tune the compromise. A one-zone equivalent model [7, 8, 13] could be an interesting simplification but the multi-0D modeling choice follows from the instrumentation of the 3WCC parametrization experiments (Sect. 3) ensuring to measure directly the zones model temperatures.

Basically, the physical phenomena are described by partial differential equations involving the three space dimensions. These equations are simplified by considering only the longitudinal dimension and discretizing this variable. Thus the model includes several zones that exchange heat with one another. A zone represents a radial slice of the $3 \mathrm{WCC}$ monolith which is assumed to be cylindrical. The zones are numbered in increasing order, with index $x \in \mathbb{N}$, from the entry zone 1 .

7o The model is based on the following assumptions:

- the heat transfers between the solids and the ambient air are negligible compared with the other transfers, 
- the same gas flow rate goes through the $3 \mathrm{WCC}$ and its zones, the exhaust gas flow rate $\dot{m}_{g}$.

${ }_{75}$ The model equations are first presented, before summarizing the variables and parameters and their type.

\subsection{OD modeling}

A monolith zone is considered as a solid mass containing exhaust gas. From the heat equation, the evolution for the current zone $x$ of the solid $T_{s x}$ and gas $T_{g x}$ temperatures can be deduced as:

$$
\Delta T_{s x}=\frac{\sum \Delta Q_{(s)(g)}}{m_{s x} C_{p}}, x \geq 1
$$

and

$$
\Delta T_{g x}=\frac{\sum \Delta Q_{(s)(g)}}{m_{g x} C_{v}}, x \geq 1,
$$

where $Q_{(s)(g)}$ are the heat transfers, $m_{s x}$ and $m_{g x}$ are the solid and gas masses, respectively, and $C_{p}$ and $C_{v}$ are the specific heat capacities. Assuming that the gas is ideal, the mass $m_{g x}$ can be given by:

$$
m_{g x}=\frac{T_{0} \rho V_{g x}}{T_{g x}}, x \geq 1,
$$

where $\rho$ is the air density at $0^{\circ} C, V_{g x}$ the gas volume in the zone and $T_{0}$ is $273 K$.

Different types of heat transfer $Q_{(s)(g)}$ influence the evolution of the temperatures:

- convection between solid and gas inside the zone $x$ :

$$
Q_{s g x}=S_{s g} c_{\text {conv }}\left(T_{g x}-T_{s x}\right), x \geq 1,
$$

where $S_{s g}$ is the surface between solid and gas and $c_{\text {conv }}$ the convective coefficient,

- conduction between the solids of two successive zones:

$$
Q_{s x, x+1}=\frac{S_{x, x+1} \lambda}{d_{x, x+1}}\left(T_{s x+1}-T_{s x}\right), x \geq 1,
$$

where $S_{x, x+1}$ and $d_{x, x+1}$ are respectively the surface and the distance between the centers of the solids of the zones $x$ and $x+1$ and $\lambda$ is the monolith conductive coefficient, 
- gas mass transfer between two zones:

$$
Q_{g x, x+1}=\dot{m}_{g} C_{v}\left(T_{g x+1}-T_{g x}\right), x \geq 0
$$

with $T_{g 0}=T_{g}$, the engine exhaust gas temperature.

\subsection{Conversion of pollutant emissions}

The solids of the zones can receive heat from the exothermic chemical reactions of pollutant emission conversion. For each zone $x$ and each pollutant species $i \in\left\{C O, H C, N O_{X}\right\}$, the conversion reaction heat is given by:

$$
Q_{x i}=a_{i} \dot{m}_{x i n i} \eta_{T i}\left(T_{s x}\right) \eta_{q}\left(t_{r x}\right), x \geq 1,
$$

where $a_{i}$ is the conversion heat coefficient, $\dot{m}_{x i n i}$ the entering pollutant flow rate (with, for the first zone, $\dot{m}_{1 i n i}=\dot{m}_{e x h}$ ), and $\eta_{T i}$ and $\eta_{q}$ are conversion efficiency functions depending respectively on the temperature and residence time $t_{r x}=\frac{m_{g x}}{\dot{m}_{g}}$. As represented on Fig. 1, the hotter the 3WCC is, the better the conversion efficiencies are, and, at low residence times (high exhaust gas flow rate), the conversion falls.
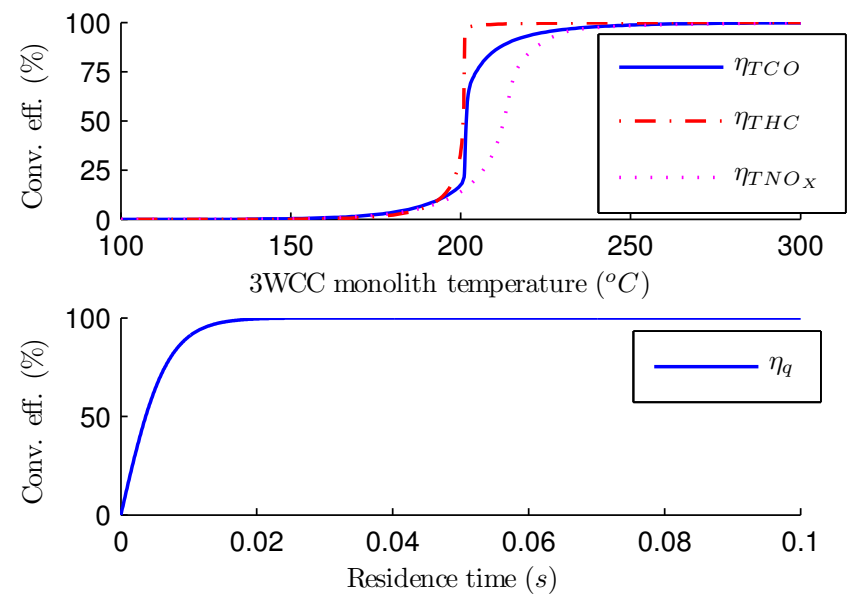

Figure 1: Conversion efficiency functions with respect to temperature (up) and residence time (down)

The flow rate of pollutant $i$ leaving zone $x, \dot{m}_{x \text { out } i}$, can be computed according to $\eta_{T i}$ and $\eta_{q}$ with:

$$
\dot{m}_{x \text { out } i}=\dot{m}_{x i n i}\left(1-\eta_{T i}\left(T_{s x}\right)\right)\left(1-\eta_{q}\left(t_{r x}\right)\right) .
$$


But this modeling is not sufficient because of the complexity of the chemical conversion mechanisms and the flow rate/monolith temperature crossing effects on conversion. To overcome this problem, global 3WCC conversion efficiencies $\eta_{3 W C C} i$ are mapped with respect to the monolith temperature at the center of the $3 \mathrm{WCC}, T_{s X}$, and the exhaust gas flow rate, $\dot{m}_{g}$, from test bench experiments. Fig. 2 shows the $C O$ conversion efficiency map, where the inputs have been normalized for confidentiality. This conversion map is more precise than the two functions $\eta_{T C O}$ and $\eta_{q}$ used in (8), represented in Fig. 1.

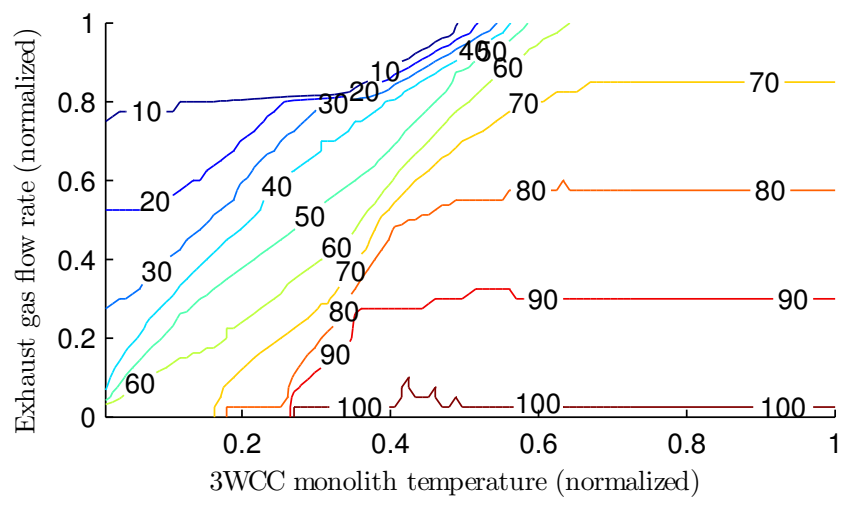

Figure 2: Test bench experiments-based $C O$ conversion efficiency map

Then the flow rate at the $3 \mathrm{WCC}$ exit for pollutant $i, \dot{m}_{3 W C C} i$, can be estimated by:

$$
\dot{m}_{3 W C C i}=\dot{m}_{e x h i}\left(1-\eta_{3 W C C i}\left(T_{s X}, \dot{m}_{g}\right)\right) .
$$

Note that (7) and (8) are used to determine the evolution of the 3WCC temperatures $T_{s x}$, particularly $T_{s X}$, which in turn is used in (9) to compute the $3 \mathrm{WCC}$ conversion efficiencies.

\subsection{Variables and parameters}

For $i \in\left\{C O, H C, N O_{X}\right\}$ the standardized pollutant emissions, $x \in \mathbb{N}$ the zone number, we now summarize the variables and parameters involved in the 3WCC model presented above, the rest of the variables being internal states:

- model inputs: engine exhaust gas temperature $T_{g}$, flow rate $\dot{m}_{g}$, and pollutant flow rates $\dot{m}_{e x h i}$, 
- model outputs: monolith temperature at the center of the $3 \mathrm{WCC}, T_{s X}$, 3WCC exit pollutant flow rates $\dot{m}_{3 W C C} i$,

- number of zones, chosen as a compromise between model simplicity and accuracy of the results,

- model parameters deduced from the 3WCC physical characteristics: $m_{s x}$, $V_{g x}, S_{s g}, S_{x x+1}, d_{x x+1}$,

- maps: global efficiencies of the $3 \mathrm{WCC}$ conversion $\eta_{3 W C C}$, built from experiments, two conversion maps $\eta_{T i}$ and $\eta_{q}$, deduced from the literature,

- two groups of free model parameters which are to be determined from different experiments: on one hand, the thermal coefficients, i.e. the specific heat capacities $C_{v}, C_{p}$, convective coefficient $c_{c o n v}$, monolith conductive coefficient $\lambda$; on the other hand, the conversion heat coefficients $a_{i}$. The thermal coefficients are not directly identifiable from experimental data, insofar as they appear in ratios, such as $\frac{c_{c o n v}}{C_{p}}, \frac{c_{c o n v}}{C_{v}}$, or $\frac{\lambda}{C_{p}}$, in the thermal equations of Sect. 1.1 .

The next Section describes the procedure for determining these free parameters.

\section{Model parametrization}

The test bench includes a 3-cylinder gasoline engine with its associated 3 WCC. The monolith is a one-block ceramic substrate. The most important measured variables are: engine exhaust gas temperature $T_{g}$, fuel consumption and Air-fuel Ratio (AFR) allowing engine gas flow rate $\dot{m}_{g}$ to be estimated, engine pollutant flow rates $\dot{m}_{\text {exh }}, 3 \mathrm{WCC}$ exit pollutant flow rates $\dot{m}_{3 W C C}$, and 3WCC monolith temperatures at different points. Two types of experiments are carried out:

- cooling phases applied on the hot 3WCC to determine the thermal coefficients,

- driving cycle-like phases to determine the conversion heat coefficients $a_{i}$ and to validate the model. 


\subsection{Thermal behavior}

Cooling phases are applied when, after regular operation, the engine is operating without combustion. The hot $3 \mathrm{WCC}$ is crossed by a cold air flow rate without pollutant emissions to convert $\left(Q_{x i}=0\right.$ in (7)). A seven-zone model is chosen and thermocouples are regularly positioned along the longitudinal axis of the $3 \mathrm{WCC}$, at the center of the radial zones, measuring the temperatures, noted in this Section $T_{s x}(t), x \in\left\{\frac{1}{4}, \frac{1}{2}, \frac{3}{4}\right\}$, at $1 / 4,1 / 2$ and $3 / 4$ of the monolith length. Two zones are considered between the zones equipped with thermocouples to simulate the monolith thermal dynamics. Fig. 3 shows the measured and estimated temperatures during a cooling phase with parameters tuned as in Table 1. These results show that a sim-

ple parametrization for the 3WCC multi-0D five-zone model is sufficient to obtain the main monolith thermal dynamics.

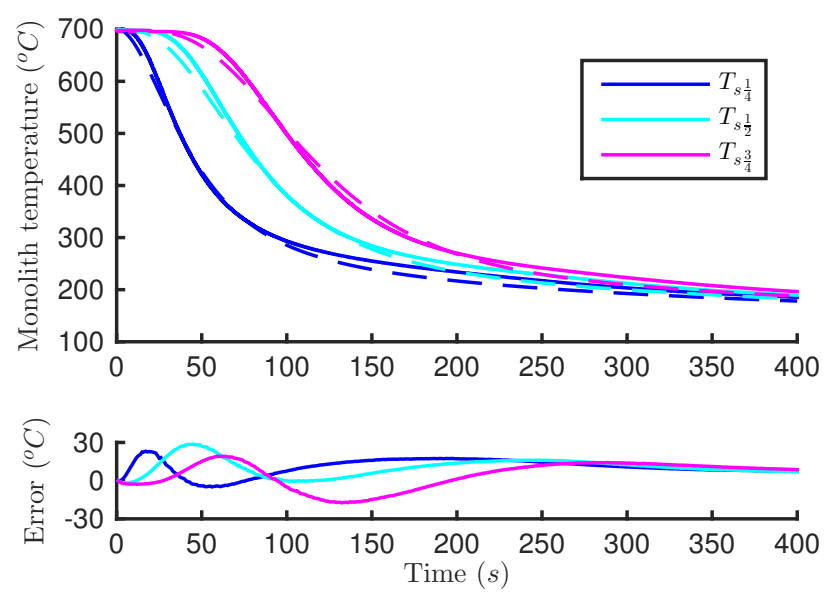

Figure 3: Measured and estimated temperatures $T_{s x}(t)$ at $1 / 4,1 / 2$ and $3 / 4$ of the monolith length during a cooling phase

\begin{tabular}{|c|c|}
\hline$C_{v}$ & $1000 \mathrm{~J} / \mathrm{m}^{3} . \mathrm{K}$ \\
\hline$C_{p}$ & $1070 \mathrm{~J} / \mathrm{kg} . \mathrm{K}$ \\
\hline$c_{\text {conv }}$ & $4000 \mathrm{~W}^{2} / \mathrm{k}$ \\
\hline$\lambda$ & $1 \mathrm{~W} . \mathrm{m} / \mathrm{k}$ \\
\hline
\end{tabular}

Table 1: Thermal coefficients tuned during cooling phases experiment to define the $3 \mathrm{WCC}$ thermal behavior (1) to (6) 


\subsection{Conversion heat coefficients}

Now, the $3 \mathrm{WCC}$ is crossed by the engine exhaust gas of a vehicle placed on a chassis dynamometer. A real driver follows a Worldwide harmonized Light vehicles Test Cycle (WLTC). A five-zone model is chosen. For pollutant heat conversion coefficients tuned as in Table 2, Table 3 gives the relative errors in $\%$ between measured and estimated pollutant emissions, cumulated over the cycle. The model gives estimated pollutant emissions slightly smaller than the measured.

\begin{tabular}{|c|c|}
\hline$a_{C O}$ & $10.000 \mathrm{~kJ} / \mathrm{kg}$ \\
\hline$a_{H C}$ & $12.000 \mathrm{~kJ} / \mathrm{kg}$ \\
\hline$a_{N O_{X}}$ & $40.000 \mathrm{~kJ} / \mathrm{kg}$ \\
\hline
\end{tabular}

Table 2: Pollutant conversion heat coefficients $a_{i}(7)$ tuned during parametrization WLTClike phase to define the $3 \mathrm{WCC}$ conversion reaction heat

\begin{tabular}{|ccc|}
\hline$C O$ & $H C$ & $N O_{X}$ \\
\hline-2 & -6 & -18 \\
\hline
\end{tabular}

Table 3: Pollutant emission relative errors (\%) at the end of the parametrization WLTClike phase

The corresponding Root Mean Square Error (RMSE) for the main temperature $T_{s X}$ (the monolith temperature at the center of the $3 \mathrm{WCC}$ ) is $47^{\circ} \mathrm{C}$. Fig. 4 shows the measured $T_{s X}$ and simulated $\hat{T}_{s X}$ temperatures, and the cumulative pollutant emissions, expressed in percentage of the total over the cycle. It can be noted that the main trends are kept by the model. Particularly, the temperature is accurately estimated during the $3 \mathrm{WCC}$ heating, at the driving cycle start, what is important because, from simulation results of the 3WCC heating (Sect. 3), on-line heuristic strategies will be finally built (Sect. 4).

Other WLTC-like phases (Valid.1 and Valid.2) were carried out to validate the model. Results are given in Table 4. Globally the model can predict the pollutant emissions. Final pollution deviation results between $-50 \%$ and $50 \%$ can be considered as acceptable results considering the simplicity of the model which remains the main constraint. A solution to increase the 

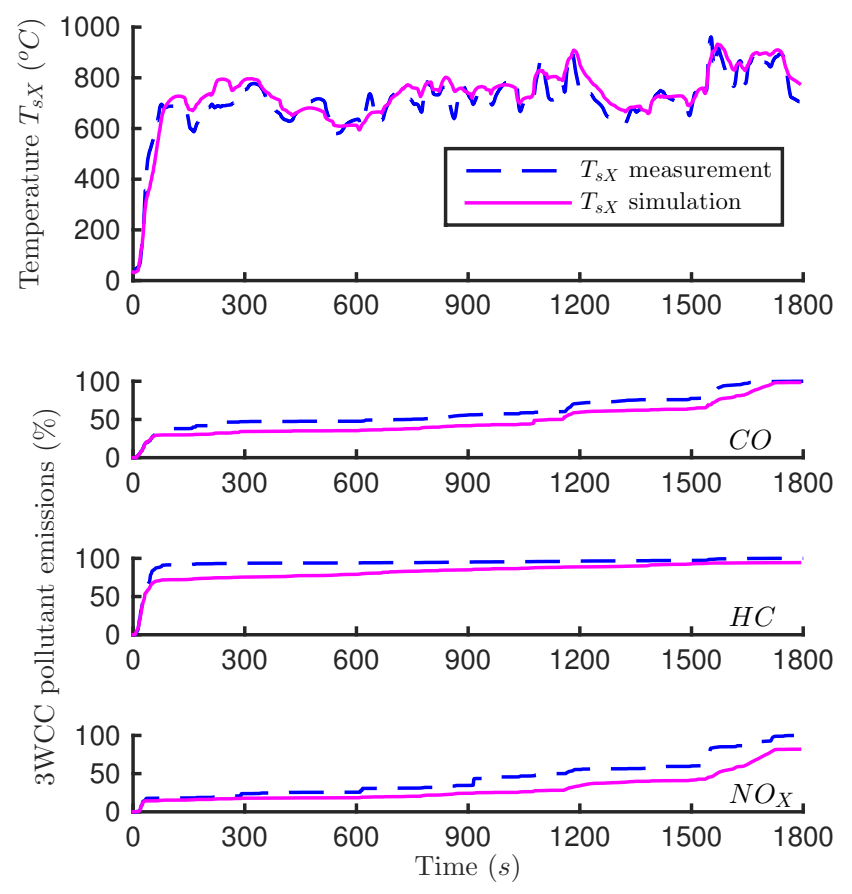

Figure 4: Measured $T_{s X}(t)$ and simulated $\hat{T}_{s X}(t)$ temperatures $\left({ }^{\circ} C\right)$ (top) and cumulative vehicle pollutant emissions $\dot{m}_{3 W C C i}(t)$ (\%) (CO,HC and $N O_{X}$ from top to bottom) during a WLTC

model accuracy and find better parameters could surely be obtained with more WLTC-like phases which are hard to perform and expensive due to the instrumentation complexity especially for the pollution analysis. The deviations are due to different ambient conditions and different drivers, who have a strong impact on pollutant emissions flow rates $\dot{m}_{\text {exh } i}$ by stressing differently the engine. The model pollution deviations are not problematic because the model will be used in simulation with an "ideal" driver model, to compare different energy management strategies with a reference and to evaluate the potential pollution reduction of pollution constraint integration.

\section{Optimal energy management}

The multi-0D five-zone 3WCC model is integrated in the high-fidelity gasoline $\mathrm{HEV}$ powertrain model which is able to generate the $3 \mathrm{WCC}$ model 


\begin{tabular}{|c|ccc|c|}
\hline & $C O$ & $\begin{array}{c}H C \\
\text { rel.val. }(\%)\end{array}$ & $N O_{X}$ & $\begin{array}{c}T_{s X} \\
\text { RMSE in }{ }^{\circ} C\end{array}$ \\
\hline Valid.1 & 0 & 43 & 3 & 49 \\
Valid.2 & -10 & 6 & -30 & 57 \\
\hline
\end{tabular}

Table 4: Validation results of the validation WLTC-like phases Valid.1 and Valid.2

inputs. High-fidelity vehicle models are forward looking models used to simulate operating and evaluate accurately the fuel consumption of innovative powertains [15, 16]. Such models ensure the powertrain sizing and the energy management development [17, 18]. In this paper the high-fidelity HEV model is a model developed by PSA Peugeot Citroën.

The HEV is a parallel mild-hybrid vehicle with the electrical machine connected to the engine by a belt (Fig. 5). This architecture allows regenerative braking, hybrid and zero-emissions vehicle (ZEV) modes. Due to architecture, during the ZEV mode, the engine injection is cut off and the electrical machine produces power, keeping the engine rotating. Then, during the ZEV phases, a gas flow rate enters the $3 \mathrm{WCC}$ and cools the monolith.

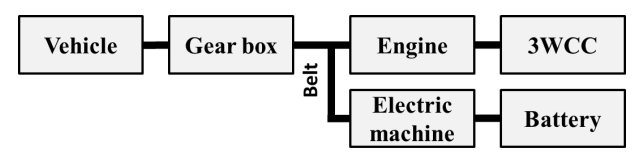

Figure 5: HEV parallel mild-hybrid architecture

\subsection{Torque split control}

The driver tracks the driving cycle speed by the accelerator and brake pedals. The requested torque $T_{0}(t)$ at the input of the gear-box can be deduced from these requests, by taking into account different gear-box and transmission ratios and efficiencies. In this work, the gear-box ratios are imposed and not optimized. This requested torque can be supplied by the engine or by the electrical machine:

$$
T_{0}(t)=T_{\text {elec }}(t)+T_{\text {eng }}(t),
$$

where $T_{\text {elec }}(t)$ and $T_{\text {eng }}(t)$ are respectively the electrical and engine torques expressed in the crankshaft referential. So, the energy management strategies 
use a torque split variable $u(t)$ representing the electrical part of the traction:

$$
u(t)=\frac{T_{\text {elec }}(t)}{T_{0}(t)} .
$$

Depending on the values of the torque split $u(t)$ and requested torque $T_{0}(t)$,

the vehicle is operated in different modes: electrical traction (Zero Emissions Vehicle), boost, pure thermal traction, and recharging mode.

The goal of the energy management strategy is to determine the control variable $u(t)$ firstly by minimizing only the fuel consumption, secondly by adding a pollutant constraint.

\subsection{Fuel consumption minimization}

The HEV model is simplified by considering a simple internal resistance model of the battery State Of Charge (SOC) dynamics:

$$
S \dot{O} C(t)=f(S O C(t), u(t)) \text {. }
$$

The off-line strategy has to minimize the performance index:

$$
\begin{array}{r}
J_{\text {fuel }}(\operatorname{SOC}(t), u(t))=\phi\left(S O C\left(t_{f}\right), t_{f}\right) \\
+\int_{t_{0}}^{t_{f}} \dot{m}_{\text {fuel }}(u(t), t) d t
\end{array}
$$

where $\dot{m}_{f u e l}$ is the fuel consumption, given from a map, and $\phi$ is a final battery SOC sustaining constraint:

$$
\phi\left(S O C\left(t_{f}\right), t_{f}\right)= \begin{cases}0 & \text { if } S O C\left(t_{f}\right)=S O C\left(t_{0}\right) \\ \infty & \text { else. }\end{cases}
$$

The Hamiltonian

$$
\begin{aligned}
H\left(S O C(t), u(t), \lambda_{1}(t), t\right)= & \dot{m}_{f u e l}(u(t), t) \\
& +\lambda_{1}(t) S \dot{O} C(t)
\end{aligned}
$$

is introduced, where $\lambda_{1}(t)$ is the co-state associated to the SOC state, respecting

$$
\dot{\lambda}_{1}^{T}(t)=-\frac{\partial H\left(S O C(t), u(t), \lambda_{1}(t), t\right)}{\partial S O C}
$$


According to the Pontryagin Minimum Principle (PMP), the optimal control $u^{*}(t)$ minimizing $(13)$ is found as

$$
u^{*}(t)=\underset{u \in E}{\operatorname{argmin}} H\left(S O C(t), u(t), \lambda_{1}(t), t\right),
$$

where $E$ is the admissible control space taking into account the constraints on the HEV components.

Assuming that the variations of the battery internal resistance and open circuit voltage are negligible compared to those of the SOC leads to:

$$
\dot{\lambda}_{1}^{T}(t)=0
$$

in the case of a HEV, for a given driving cycle [19]. Thus, $\lambda_{1}$ is taken constant and a simple binary search yields the value that minimizes HEV fuel consumption while ensuring charge sustaining.

\subsection{Pollution consideration}

To consider pollution, we define an augmented performance index [1]:

$$
\begin{array}{r}
J_{\text {mixed }}\left(S O C(t), T_{s X}(t), u(t)\right)=\phi\left(S O C\left(t_{f}\right), t_{f}\right) \\
+\int_{t_{0}}^{t_{f}} \dot{m}_{\text {mixed }}\left(u(t), T_{s X}(t), t\right) d t
\end{array}
$$

where $\dot{m}_{\text {mixed }}$ is a mixed pollution/fuel consumption flow rate defined by:

$$
\begin{array}{r}
\dot{m}_{\text {mixed }}\left(u(t), T_{s X}(t), t\right)=\dot{m}_{\text {fuel }}(u(t), t) \\
+\alpha \sum_{i} \frac{\dot{m}_{3 W C C i}\left(u(t), T_{s X}(t), t\right)}{s t d_{i}}
\end{array}
$$

where the $\dot{m}_{3 W C C} i$ are the flow rates at the $3 \mathrm{WCC}$ exit for pollutant $i$, $i \in\left\{C O, H C, N O_{X}\right\}(9)$, the $s t d_{i}$ are the acceptable pollution limits of the Euro $\mathrm{V}$ standard, and $\alpha$ is the single, global, trade-off tuning parameter.

To minimize (19), in addition to $S O C$, with dynamics (12), the monolith center temperature $T_{s X}$ is considered in the PMP resolution, with dynamics:

$$
\dot{T}_{s X}(t)=g\left(T_{s X}(t), u(t)\right)
$$


This dynamics can be analytically calculated from (1), (2), (3) and (9), but, to reduce the computation time, a simplified form is chosen. The Hamiltonian is now:

$$
\begin{array}{r}
H\left(S O C(t), T_{s X}(t), u(t), \lambda_{1}(t), \lambda_{2}(t), t\right) \\
=\dot{m}_{\text {mixed }}(u(t), t)+\lambda_{1}(t) S \dot{O} C(t)+\lambda_{2}(t) \dot{T}_{s X}(t) .
\end{array}
$$

As previously, $\lambda_{1}(t)$, taken constant, is determined by binary search to ensure charge sustaining. The second co-state $\lambda_{2}(t)$ evolves as:

$$
\dot{\lambda}_{2}^{T}(t)=-\frac{\partial H\left(S O C(t), T_{s X}(t), u(t), \lambda_{1}(t), \lambda_{2}(t), t\right)}{\partial T_{s X}},
$$

according to the PMP, giving a closed form:

$$
\lambda_{2}(t)=\lambda_{20} e^{f_{1}\left(T_{s X}(t), u(t), t\right)}-f_{2}\left(T_{s X}(t), u(t)\right)
$$

where $f_{1}$ and $f_{2}$ are two functions deduced from the simplified form chosen to approximate (21). Finally, the optimal control $u^{*}(t)$ minimizing (19) can be found by minimizing (22):

$$
u^{*}(t)=\underset{u \in E}{\operatorname{argmin}} H\left(S O C(t), T_{s X}(t), u(t), \lambda_{1}(t), \lambda_{2}(t), t\right) .
$$

220

with $\lambda_{2}(t)$ computed with (24).

The strategy is tuned with 2 parameters: $\alpha(20)$ and $\lambda_{20}(24)$. In [9, 11, 1, it was shown that tuning $\alpha$ with $\lambda_{20}=0$ gives better results than tuning $\lambda_{20}$. Choosing $\lambda_{20}=0$ implies constraining pollution, without any constraints on the $3 \mathrm{WCC}$ temperature $T_{s X}$. All results presented below were obtained with $\lambda_{20}=0$.

\subsection{Simulation Results}

The fuel consumption minimization strategy is implemented in the HEV model supervisory control and the corresponding optimal control $u^{*}(t)$ (17) is applied to the HEV model. Next variations of $\alpha$ in $(20)$ make it possible to explore trade-offs between pollution and fuel consumption when applying $u^{*}(t)$ (25) to the HEV.

The simulation results are charge sustaining constrained, with a binary search of the constant $\lambda_{1}$. Table 5 gives, for different fuel consumption/pollution compromises $\alpha$, the relative variations in $\%$ of the fuel consumption and pollutant emissions, cumulated on a WLTC, w.r.t the reference, where only the 


\begin{tabular}{|c|c|c|c|c|}
\hline$\alpha$ & Fuel Cons. & $C O$ & $H C$ & $N O_{X}$ \\
\hline 0.2 & 0.06 & -7.7 & -1.4 & -3.2 \\
0.4 & 0.17 & -11.4 & -3.2 & -9.4 \\
0.5 & 0.18 & -11.8 & -4.1 & -10.3 \\
0.6 & 0.25 & -12.1 & -5.6 & -10.8 \\
\hline
\end{tabular}

Table 5: WLTC simulations relative variations (\%) of fuel consumption and pollutants

fuel consumption is minimized. Good results are obtained with the pollution constrained optimal energy management strategy. As the trade-off parameter $\alpha$ increases, the pollution decreases with little impact on fuel consumption. Fig. 6 shows simulation trajectories of the $S O C(t)$ and $T_{s X}(t)$ states for the reference, $\alpha=0.2$ and $\alpha=0.6$ compromises. $\alpha=0.6$ is the largest
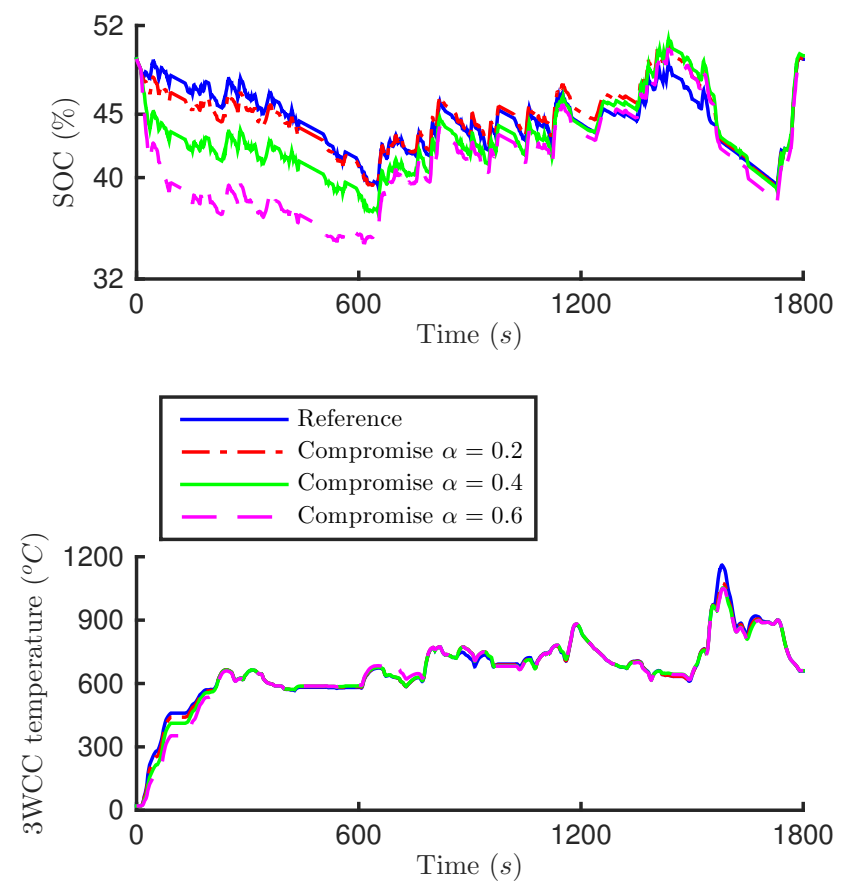

Figure 6: States $S O C(t)(\%)(t o p)$ and $T_{s X}(t)\left({ }^{\circ} C\right)$ (bottom) trajectories

admissible value. Greater values drain the battery and get the SOC to cross the health boundary. In Fig. 6, it can be seen that the larger the tradeoff parameter $\alpha$ is, the more slowly the 3WCC is heated at beginning while 
reaching the same temperature at $300 \mathrm{~s}$. This can be expressed as smart 245 heating: at the beginning of the driving cycle, to produce less pollution when heating the $3 \mathrm{WCC}$, the electrical machine $\left(T_{\text {elec }}>0\right)$ helps the engine to produce the requested torque $T_{0}$. The decrease of the battery $S O C$ is caught up later during recharging phases. The corresponding reduction of pollutant emissions during the 3WCC heating can be seen in Fig. 7. From these observations, online heuristic strategies are derived and described in the next Section.
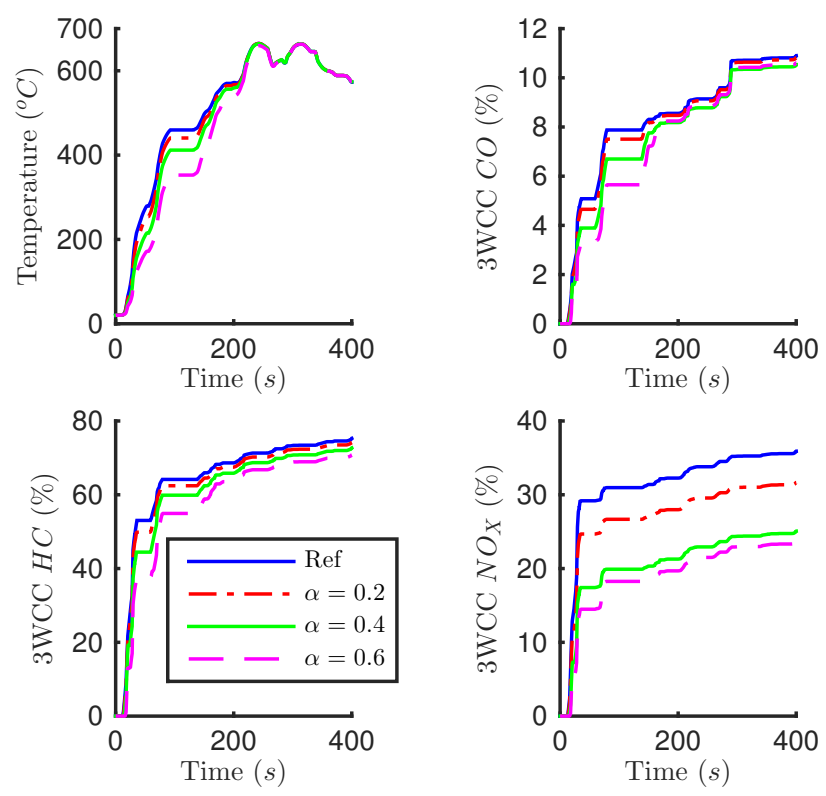

Figure 7: Temperature $T_{s X}(t)\left({ }^{\circ} C\right)$ (top left), $C O$ (top right), $H C$ (bottom left), and $N O_{X}$ (bottom right) cumulative vehicle pollutant emissions flow rates $\dot{m}_{3 W C C i}(t)(\%)$

\section{Experimental validation}

\subsection{HyHIL test bench}

The HyHIL test bench, shown Fig. 8, is composed of an engine connected to a high-dynamics generator with a transmission. Similar HyHIL experiments have been described in [7, 10, 20]. The engine is equipped with the 3WCC modeled in Sect. 1. A vehicle model, similar to the one of the previous Section, is implemented in the test bench supervision software and simulated in real-time (see Fig. 9). A driver model controls the vehicle speed 


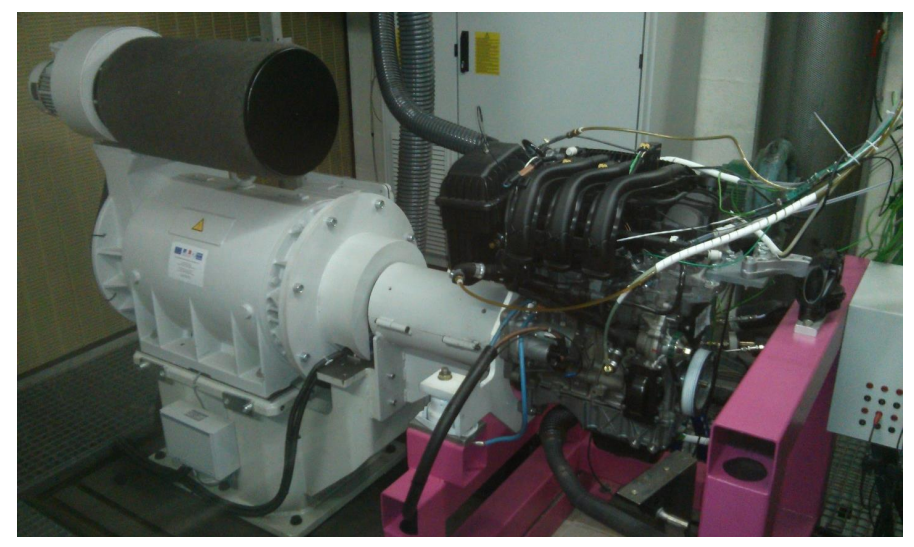

Figure 8: Test bench with the high-dynamics generator (left, in white) and the engine (right) on the chassis (right, in pink)

to track the WLTC speed set-point. The requested torque $T_{0}(t) \sqrt{10}$ is deduced from the driver demand and on-line energy management strategies calculate the torque-split command $u(t)$ (11), and then the electrical $T_{\text {elec }}(t)$ and engine $T_{\text {eng }}(t)$ torque commands from (10) and (11). The engine torque is measured with a torque-meter on the transmission and used by the vehicle model to compute the engine speed set-point. The supervision software ensures the engine speed control.

\subsection{On-line heuristic strategies}

Two on-line heuristic energy management strategies are defined: a Charge Sustaining $(C S)$ strategy and a Smart Heating $(S H)$ strategy. The CS strategy determines the engine stop/start from the requested torque $T_{0}$ with a map $M_{O N / O F F}$ depending on the engine speed $\omega_{\text {eng }}$, according to:

- if $T_{0}(t)<M_{O n / O f f}\left(\omega_{\text {eng }}\right), u(t)=1$

- else $u(t)=M_{C S}(S O C(t))$,

where $M_{C S}(S O C(t))$ is a second map ensuring the battery sustaining at $60 \%$. The first objective of the CS strategy is to ensure to use the ZEV mode, from the map $M_{O n / O f f}$, when the engine efficiency is low [19]. A second objective is to sustain the battery SOC from the map $M_{C S}$. If the battery is discharged, $u(t)<0\left(T_{\text {eng }}(t)>T_{0}(t)\right)$, and the engine recharges the battery. If the battery is overcharged, $u(t)>0\left(T_{\text {eng }}(t)<T_{0}(t)\right)$, and the electrical machine takes part in the traction. 


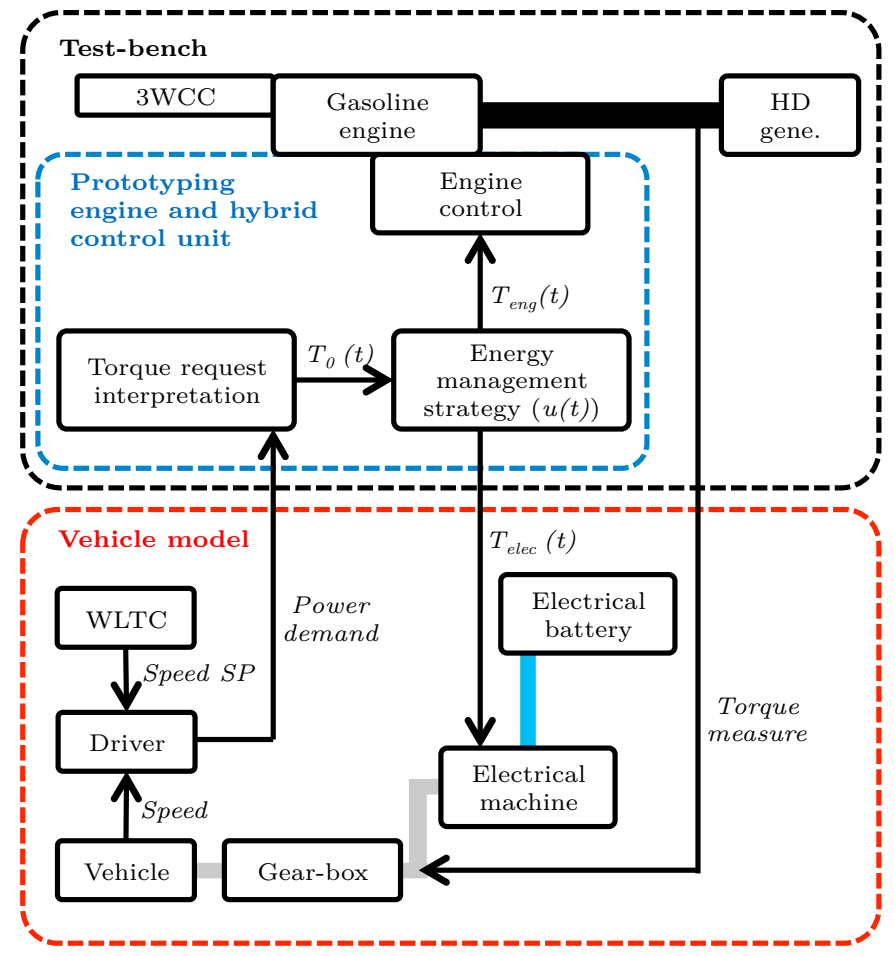

Figure 9: HyHIL test bench of a HEV parallel mild-hybrid architecture

The SH strategy ensures smart heating of the 3WCC, as observed in Sect. 3.4, with the rules:

- if $T_{s X}(t)<160^{\circ} \mathrm{C}$

- if $T_{0}(t)<T_{\text {elec } \max }(t), u(t)=1$

285

- else $u(t)=\frac{T_{\text {elec } \max }(t)}{T_{0}(t)}$

- elseif $160^{\circ} C<T_{s X}(t)<500^{\circ} C$

- if $T_{0}(t)<M_{\text {On/Off }}\left(\omega_{\text {eng }}\right), u(t)=1$

- else $u(t)=0$

- else (CS strategy)

- if $T_{0}(t)<M_{O n / O f f}\left(\omega_{\text {eng }}\right), u(t)=1$ 


$$
\text { - else } u(t)=M_{C S}(S O C(t))
$$

where the $3 \mathrm{WCC}$ temperature $T_{s X}(t)$ is measured or estimated and $T_{\text {elec max }}(t)$ is the maximum electrical torque. The main objective of the SH strategy is to make maximum use of electricity when $T_{s X}(t)$ is under a $160^{\circ} \mathrm{C}$ threshold.

When $T_{s X}(t)$ is between $160^{\circ} \mathrm{C}$ and $500^{\circ} \mathrm{C}$, the engine start is decided with the CS strategy map $M_{O n / O f f}\left(\omega_{\text {eng }}\right)$ but the charge sustaining objective is not activated. This rule is used because the $3 \mathrm{WCC}$ is not fully lightened and the vehicle pollutant emissions are higher if the engine is overloaded to recharge the battery $(u(t)<0)$. When $T_{s X}(t) \geq 500^{\circ} C$, the battery charge is sustained and the CS strategy is totally activated. The battery will be recharged by using the engine $\left(u(t)<0\right.$ and $\left.T_{\text {eng }}>T_{0}(t)\right)$ with a good $3 \mathrm{WCC}$ conversion efficiency.

The thresholds $160^{\circ} \mathrm{C}$ and $500^{\circ} \mathrm{C}$ have been chosen to obtain a significant pollutant emissions decrease and a SOC evolution representative of the simulations results (Fig. 6). The first threshold $\left(160^{\circ} \mathrm{C}\right)$ is the most sensitive. A higher threshold leads to a non-representative battery discharge and a smaller threshold gives non-significant pollution decrease. The second threshold $\left(500^{\circ} \mathrm{C}\right)$ is chosen to prevent high pollutant emissions occurring at engine overloads. A higher threshold inhibits the battery recharge and a smaller threshold increases the pollution due to overloads.

\subsection{Experimental results}

CS and SH strategies are implemented on the HyHIL test bench. Fig. 10 shows simulated $S O C$, measured temperature $T_{s X}$ and cumulative pollutant emissions flow rates $\dot{m}_{e x h i}$ and $\dot{m}_{3 W C C}$.

CS strategy is able to sustain the $S O C$ around $60 \%$ as expected. Both the heuristic strategies heat the $3 \mathrm{WCC}$ at the same temperature at $300 s$, but SH strategy uses more electricity at the cycle start to reproduce the smart heating observed in simulation (Sect. 3.4). During the first $300 \mathrm{~s}$, the measured temperature $T_{s X}$ is lower because the ZEV and hybrid modes are often used. The engine is less often operated and engine emissions $\dot{m}_{e x h i}$ are lower. It is worth noting that the $C O$ and $N O_{X}$ vehicle emissions $\dot{m}_{3 W C C} i$ with the CS strategy are reduced respectively by $30 \%$ and $10 \%$. Besides, HC vehicle emissions are increased by $15 \%$ because of a pipe wetting phenomenon during the injection cut-offs, caused by the prototyping engine control. The problem is well-known [21, 22] and is corrected in production vehicle engine control. 

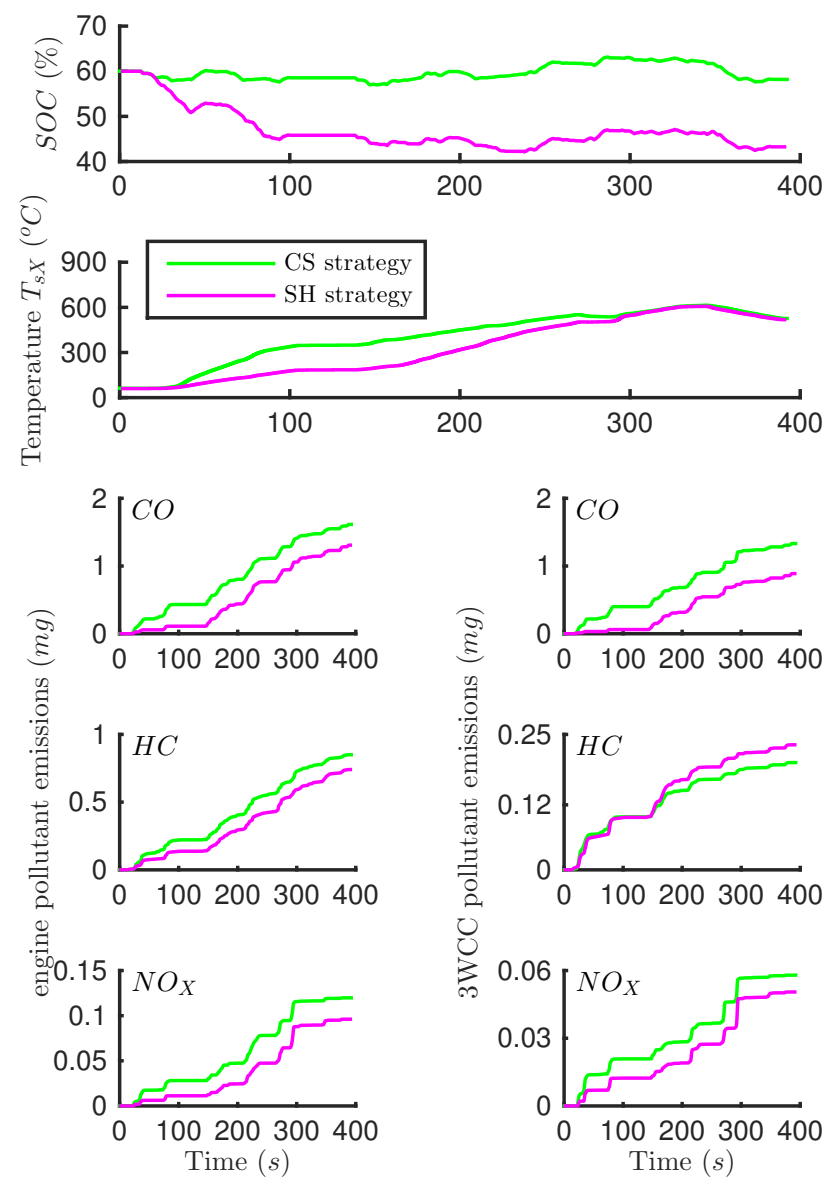

Figure 10: From top to bottom, simulated $S O C(t)(\%)$, measured 3WCC temperature $T_{s X}(t)\left({ }^{o} C\right)$, cumulative engine (left) $\dot{m}_{e x h i}(t)$ and vehicle (right) $\dot{m}_{3 W C C i}(t) C O, H C$ and $N O_{X}$ pollutant emissions flow rates $(m g)$ with CS (green) and SH (pink) strategies

If the cut-offs $H C$ emissions are removed, a $H C$ vehicle emissions reduction by $5 \%$ can be expected.

\section{Conclusion}

A 3WCC multi-0D model has been built from physical equations, integrating the $3 \mathrm{WCC}$ temperature dynamics and a pollutant emission conversion map. The validated model, with suitable complexity and performances, was included in a high-fidelity gasoline-HEV powertrain model. 
Next, a pollutant constrained optimal energy management was derived from the Pontryagin Minimum Principle. The approach allowed the joint minimization of pollution and fuel consumption with only one parameter to tune, by considering all the standardized pollutant emissions. In simulations, the proposed strategy reduced significantly the vehicle $C O$ and $N O_{X}$ emissions for a minor fuel consumption increase. Analyzing the HEV operation ensuring these results permited to define a $3 \mathrm{WCC}$ smart heating.

Thus a HyHIL was used to implement two on-line heuristic strategies: a classical charge sustaining strategy and a 3WCC smart heating strategy. The HyHIL allows to simulate the vehicle driving in real-time with the real engine and its associated 3WCC. The smart heating strategy showed good results and can reduce the charge sustaining strategy pollutant emissions. $30 \% C O$ and $10 \% N O_{X}$ pollutant emissions reduction have been measured. To conclude, the 3WCC smart heating has been validated with the HyHIL experimental test bench, what confirms the modeling and optimization approaches used to build an on-line energy management strategy including a pollution constraint.

\section{References}

[1] P. Michel, A. Charlet, G. Colin, Y. Chamaillard, G. Bloch, C. Nouillant, Catalytic Converter Modeling for Optimal Gasoline-HEV Energy Management, in: Proc. 19th IFAC World Congress, Cape Town, South Africa, 2014, pp. 6636-6641.

355

[2] R. Bellman, Dynamic Programming and the Smoothing Problem, Management Science 3 (1) (1956) 111-113.

[3] L. S. Pontryagin, The Mathematical Theory of Optimal Processes, John Wiley, 1962.

[4] O. Grondin, L. Thibault, P. Moulin, A. Chasse, A. Sciarretta, Energy Management Strategy for Diesel Hybrid Electric Vehicle, in: IEEE Vehicle Power and Propulsion Conf. (VPPC), Chicago, IL, USA, 2011.

[5] F. Millo, L. Rolando, E. Servetto, Development of a Control Strategy for Complex Light-Duty Diesel-Hybrid Powertrains, SAE Technical Paper 2011-24-0076 (2011). 
[6] P. Michel, A. Charlet, G. Colin, Y. Chamaillard, C. Nouillant, G. Bloch, Energy Management of HEV to Optimize Fuel Consumption and Pollutant Emissions, in: 11th Symp. on Advanced Vehicle Control (AVEC 2012), Seoul, South Korea, 2012.

[7] A. Chasse, G. Corde, A. Del Mastro, F. Perez, Online Optimal Control of a Parallel Hybrid with After-Treatment Constraint Integration, in: IEEE Vehicle Power and Propulsion Conf. (VPPC), Lille, France, 2010.

[8] F. Merz, A. Sciarretta, J.-C. Dabadie, L. Serrao, On the Optimal Thermal Management of Hybrid-Electric Vehicles with Heat Recovery Systems, Oil Gas Sci. Technol. 67 (4) (2012) 601-612.

[9] P. Michel, A. Charlet, G. Colin, Y. Chamaillard, C. Nouillant, G. Bloch, Pollution Constrained Optimal Energy Management of a Gasoline-HEV, SAE Technical Paper 2013-24-0083 (2013).

[10] L. Serrao, A. Sciarretta, O. Grondin, A. Chasse, Y. Creff, D. Di Domenico, P. Pognant-Gros, C. Querel, L. Thibault, Open Issues in Supervisory Control of Hybrid Electric Vehicles: A Unified Approach Using Optimal Control Methods, Oil Gas Sci. Technol. 68 (1) (2013) 23-33.

[11] P. Michel, A. Charlet, G. Colin, Y. Chamaillard, C. Nouillant, G. Bloch, 3WCC Temperature Integration in a Gasoline-HEV Optimal Energy Management Strategy, Advances in Mechanical Engineering (2014) Article ID 802597.

[12] D. Kum, H. Peng, N. Bucknor, Modeling and Control of Hybrid Electric Vehicles for Fuel and Emission Reduction, in: Proc. ASME Dynamic Systems and Control Conf., Ann Arbor, MI, USA, 2008, pp. 553-560.

[13] D. Kum, H. Peng, N. K. Bucknor, Optimal Energy and Catalyst Temperature Management of Plug-in Hybrid Electric Vehicles for Minimum Fuel Consumption and Tail-Pipe Emissions, IEEE Trans. Control Syst. Technol. 21 (1) (2013) 14-26.

[14] E. D. Tate, J. W. Grizzle, H. Peng, SP-SDP for Fuel Consumption and Tailpipe Emissions Minimization in an EVT Hybrid, IEEE Trans. Control Syst. Technol. 18 (3) (2010) 673-687. 
[15] R. Vijayagopal, L. Michaels, A. P. Rousseau, S. Halbach, N. Shidore, Automated model based design process to evaluate advanced component technologies, SAE Technical Paper 2010-01-0936 (2010).

[16] S. Halbach, P. Sharer, S. Pagerit, A. P. Rousseau, C. Folkerts, Model architecture, methods, and interfaces for efficient math-based design and simulation of automotive control systems, SAE Technical Paper 201001-0241 (2010).

[17] J. Hong, S. Kim, B. Min, Drivability development based on cosimulation of AMESim vehicle model and simulink HCU model for parallel hybrid electric vehicle, SAE Technical Paper 2009-01-0725 (2009).

[18] D. Sinoquet, G. Rousseau, Y. Milhau, Design optimization and optimal control for hybrid vehicles, Optimization and Engineering 12 (1-2) (2011) 199-213.

[19] L. Guzzella, A. Sciarretta, Vehicle Propulsion Systems, Springer, 2007.

[20] F. Perez, P. Moulin, A. Del Mastro, Vehicle simulation on an engine test bed, in: Proc. SIA Conference on Diesel Engines-The low CO2 \& Emissions Reduction Challenge, Rouen, France, 2008.

[21] L. Guzzella, C. Onder, Introduction to Modeling and Control of Internal Combustion Engine Systems, 2nd Edition, Springer, 2010.

[22] J. B. Heywood, Internal Combustion Engine Fundamentals, McGrawHill, 1988. 